\title{
The Research of Scrapped Automobiles Recycling and Disassembling Industry Development Based on Auto Industry Chain
}

\author{
Pang linhua ${ }^{1,2, a}$, Wen Guilin ${ }^{1, b}$ \\ State key laboratory of advanced automobile body designing and manufacturing, School of mechanical and vehicle engineering in Hunan \\ University, Changsha, Hunan 410082, China \\ ${ }^{2}$ Torch high technology industry development center of Ministry of science and technology, Beijing 100045, China
}

\begin{abstract}
The number of China's scrapped car is on an explosively growing trend, and the development of scrapped car recycling industry has a golden prospect. The current scrapped car recycling system is not perfect in our country, because related industries driven by market develop slowly, and there are some outstanding problems such as potential safety risks, environmental pollution and resource waste. The paper analyzes and studies the existing problems and countermeasures to investigate the development strategy of scrapped car recycling industry according to the whole automobile industry chain construction, technology and equipment conditions, policy guidance, etc. and at last explore the new industrial development pattern of serving automobile reverse design.
\end{abstract}

\section{Introduction}

The development of scrapped car recycling industry must be adapted to the development of China's automobile industry. According to the Traffic Management Bureau of Ministry of Public Security, China has more than 264 million vehicles at the end of 2014, among which there have 154 million autos, ranking the second place after US in the world [1]. With the continued explosive growth of vehicles in China in recent years, the speed of car scrapping and updating rises sharply. In 2000 there are 580,000 scrapped cars, and in 2011 there are more than 4 million scrapped cars in China. It is estimated that there are more than 14 million scrapped cars in 2020. As the country that produces and sells the most vehicles in the world, China must solve the problem of recycling scrapped car and seize the opportunity to move ahead of other countries in resource utilization, environmental protection, and traffic safety.

Nowadays the technology and system of scrapped car recycling industry is quite mature in developed countries [2]. There is a big gap between the scrapped car recycling industry in China and in developed countries. Domestic vehicle scrapping system manages scrapped automobiles mainly based on traffic safety to prohibit using scrapped parts for illegally vehicle assembling, lack of consideration for environmental protection and resource recycling. Also it is lack of specific requirements and regulations about reasonable scrapped car recycling and solution to the problem of public hazards caused by scrapped car [3]. Recyclable resource of scrapped car is numerous. Take material of scrapped car as an example. Recycling revenue can reach to 3000 Yuan each car, and

\footnotetext{
a panglinhua119@163.com, ${ }^{b}$ wengl@hnu.edu.cn
}

China's scrapped auto recycling market is expected to have the scale of 30 billion Yuan. Scrapped car recycling industry in China, however, still experiences many difficulties at present, lack of stamina. Except the proverbial reason for the low level of science and technology and undeveloped related policy, there is another important restriction factor that China lacks the sense of the circular, the innovated idea of economy development and the key technology and equipment [4].

\section{The importance of policy guidance}

The development of scrapped car recycling industry is not only a market problem and industry problem, but also a social problem, which needs reasonable policy guidance and support. With high residual value, scrapped vehicles can be recycled in accordance with the market-oriented operation. However, there are high social risks to develop scrapped car recycling industry purely relying on market economic law. On one hand, at present scrapped automobiles are treat as waste materials by most related enterprises in our country, in workshop-style, lack of advanced disassembling equipment and technology, work staff with relatively low quality, which cannot guarantee recycling revenue with existing disassembling efficiency. Not to mention the low level of environmental protection, in the disassembling process waste oil, batteries, heavy metal from electronic components, and Freon-the air conditioner refrigerant will cause great pollution on soil, water and atmosphere. On the other hand, there are many illegal disassembling dens driven by profit, and they even produce assembling cars into the market, which brings a serious threat to people's safety[5]. Therefore, concerning 
about the backward views of the series of problems such as circular economy, traffic safety, and environmental pollution, scrapped car recycling policies need to play a positive role on standardizing enterprise operation, improving technology level, strengthening environmental protection and defending corporate interests, and to guide, standardize the benign development of industry through macro management.

Firstly, scrapped car recycling industry policy should attach great importance to the guiding role of enterprise standardized management and the support of advanced disassembling and recycling technology. The disassembling and recycling of scrapped car cannot be done by salvage station. It needs to cultivate professional companies to undertake the job. Scrapped automobiles and parts, for example, will cause environment pollution in the step of disassembling, crushing and recycling. If lead, chromium or mercury diffuses, the waste oil will leak into the soil directly and cause irreversible effects on the environment. Except whether enterprises attach importance to environment protection or not, the available technology is also a key reason if the environment pollution problems can be prevented. As a result, on the premise of the scientific forecast about the adverse effects each link of scrapped automobiles recycling may bring on environment, it needs to ensure strict recycling program and standardized enterprise management by law, and to support the technology growth of relevant enterprises by policy, which will help the industry obtain a healthy and sustainable development[6].

Second, it needs to improve the relevant laws and regulations as soon as possible and intensify law enforcement. According to the developing trend of circular economy and society, considering of disassembling and recycling from the angle of system engineering, balance security, environmental protection, resources utilization and other factors, it needs urgently to formulate and perfect the completed relevant mandatory standards and industry regulation system about scrapped car recycling according with national conditions of China. In particular, the relevant policies and regulations need to be proactive and avoid discontinuity, because constantly changing policies is quite hurtful to the development of emerging industries. For example, to improve the scrap subsidies for old car exchanging a new one and environmental protection subsidies in the disassembling process, which is one of the major short-term measures that affect scrapped automobiles disassembling and recycling industry, will undoubtedly improve the condition of scrapped car recycling, but once a while discontinuous policy caused the serious volatility of recovery rate[7]. On the other hand, to strengthen the law enforcement is an important support to ensure the policy is effective and defend the benefit of the relevant enterprises. Before vehicle reaching its legal service life, for example, it is determined by regular inspection whether vehicles should be scrapped. But this link relies on the qualified domestic related social service agencies and technologies, and it also needs the guarantee of law enforcement. In addition, because there are some loopholes of the current relevant supervision, driven by the interests, a large number of scrapped automobiles are sold into "black market" of illegal assembled car. After re-assembled, scrapped automobiles come into use again, which is a serious threat to traffic safety and directly leads to the problem that the enterprises of recycling and disassembling do not have enough to "eat".

In addition, it is an inevitable trend of scrapped car recycling in the circular economy society, and scrapped car recycling will also bring potentially huge economic interests. Currently many government management departments are involved in automobile scrapped car recycling policies, including the Ministry of Commerce, National Development and Reform Commission (NDRC), Public Security and Traffic Department, the Ministry of Industry and Information Technology and the Ministry of Science and Technology. How to implement the department coordination, how to efficiently manage mechanism of division of labor and ensure the seriousness of law enforcement, which are urgent issues to be solved.

\section{Advanced recycling and disassembling technology is the inevitable choice for enterprise development}

A car is a complex system involving multiple disciplines of mechanical - electro-hydraulic, composed of tens of thousands of components with different structure, material, and function. Therefore, it must adopt scientific methods and advanced technology to recycle scrapped automobiles. Scrapped automobiles recycling and disassembling is an emerging industry in our country, deeply relying on the policy, with the recycling and disassembling technology in early stage. Outdated technology is the core reason for restricting the development of the industry. Industry enterprise must develop their own core technology of increase recycling quantity, disassembling and re-utilization rate, and break through development bottleneck of prevalent low recycling and disassembling efficiency and low profit. If only relying on policy support, the enterprises will lack of vitality and space of sustainable development.

Firstly, the problem of the scrapped automobiles quantity recycled formally ought to be solved from technology level, avoiding the phenomenon of enterprises "do not have enough to eat". On one hand, it needs to improve the technical ability of scrapped car testing station, in order to ensure the standardization, rationality and fairness in the process of scrapped car test planning and solve the problem of who determines if the car is scrapped. On the other hand, it needs to develop advanced logistics network information system. At this stage, improving the scrap subsidies of old car exchange for a new one is a short-term measures which is conducive to promoting the owner voluntarily to scrap vehicle formally[8]. However, it still has to solve the convenience and habitual problem of car owner scrapping 
vehicle formally from the technology level, which requires to build to an integrated vehicle formal scrap logistics network connecting the owner, department of traffic management, testing station, dismantling enterprises, and transportation companies and vigorously develop the advanced informationalized logistics system.

Second, the viability and competitiveness of automobile disassembling enterprises depend on to a great extent the automobile disassembling technology and intellectualized equipment. The personage inside the industry says that Mercedes-Benz cars sold in Germany of Daimler company basically use recyclable components [9]. In France, some auto companies and recycling enterprises jointly established scrapped car recycling center, recycling nearly $75 \%$ of the parts. The proportion of recycled components scrapped car of in our country lagged far behind the proportion of these countries. It is not only due to vehicle producing factories and automotive spare parts factories not willing to adopt qualified recycled parts, but also due to backward low technical level of retrieving and disassembling scrapped automobiles. There are large numbers of disassembling enterprises in our country with small scale and poor specialization degree, which generally do not have advanced and reliable retrieving testing technology and remanufacturing technology and also lack advanced automatically disassembling equipment and remanufacturing equipment [10]. Some enterprise is even transformed from other disassembling industries or waste recycling companies, without the ability to identify professionally if the components can be remanufactured. Usually, scrapped car recycling involves the key technology about fatigue life evaluation of component, nondestructive test of structure and material, internal inspection, laser repair of surface damage and remanufacture of components. For key components, for example, combined with the part of the test response, calculate the reverse technology based on genetic algorithm is used to inverse the internal structure damage and fatigue life, belongs to the high efficiency and low cost of one of the nondestructive testing technology [11]. Similar to these of nondestructive testing technology is to realize the high efficiency, high quality car of retrieving and dismantling of the core technology, but at present domestic related enterprise technical strength and the high and new technology gap is obvious.

Along with our country automobile scrapping crush, retrieving and dismantling scrapped automobiles industry will usher in huge opportunities for development. Of retrieving and dismantling reuse of high and new technology will be China's automobile enterprises of retrieving and dismantling the basic way of realizing leap-forward development, is also the retrieving and dismantling scrapped automobiles industry in our country from the policy dependent to the high and new technology industry transformation.

\section{Technology synergy innovation in the automobile industry chain}

For retrieving and dismantling scrapped automobiles industry to enter, should formulate the corresponding examination and approval standards and management norms, open to the society as a whole, to encourage and cultivate professional car enterprises of retrieving and dismantling. The early stages of scrapped automobiles recycling is to solve the problem of waste vehicle "lost" anywhere. Some one-sided think scrap car recycling is disassembled recycle junk, ignores the more important parts of resources recycling [12]. With the development of modern circular economy society, retrieving and dismantling scrapped automobiles is not simple parts cleaning, repairing and reusing, it is also different from illegal dismantling dens of the vehicle assembly. Of retrieving and dismantling scrapped automobiles recycling system implement, the operation must be relying on the professional enterprise, but due to the industry involves the car design, manufacture, use and scrap the whole life cycle of each link, to encourage the automobile enterprises of retrieving and dismantling and car industry chain including vehicle, spare parts, automobile logistics and maintenance service, dismantling equipment industry and other kinds of synergy with the combination of the enterprise.

In particular, we should actively play a motor vehicle and parts production enterprises in the role of the scrap car recycling. Directly involved in the vehicle and parts production enterprises, has end in automotive product whole life cycle of the effect of echo. On the one hand, from the source, scrap recycling utilization level of auto parts to a large extent depends on these companies with qualified recycling parts will degree; , on the other hand, they can in the new product design and development of both the product recycling problem in the future, which can significantly reduce scrap auto disassembly cost, improve the utilization rate of recycling to reduce the pollution to the environment, to ensure the virtuous cycle of scrap car recycling industry. No OEMs, spare parts factory, in turn, to participate in and accept the components for remanufacturing, retrieving and dismantling scrapped automobiles can only stay at the primary stage of waste treatment. Back in 1991 America's three big car company general motors, ford and daimlerchrysler established vehicle recycling alliance (VRP), specification of scrapped automobiles recycling process, jointly funded research scrapped automobiles recycling technology, implementation technology in the field of non-compete share [13]. Development today, the United States have a perfect and mature scrapped automobiles recycling system and technology, the global scrap car recycling industry is second to none in the world.

It is worth mentioning that there are two unique industry supporting the scrap car recycling industry development, also has a good development space. One of, dismantling equipment industry. Advanced intelligent disassemble equipment is currently scrap car dismantling enterprises urgently need automated production hardware, also is the enterprise to ensure the high efficiency, high quality to complete the basic safeguard that dismantling the production task. For example, based on the 
classification of the material type and sorting require very high degree of automation of production line[14]. Second, the auto service industry, including automotive logistics and auto maintenance. Vehicle maintenance and repair services, for example, the joint participation, can give full play to their structure principle, fault diagnosis, the car parts maintenance of professional and technical advantages. Automobiles, of course, the development of the recycling industry itself also will lead to the development of other related industries, for example, can be used as road materials, waste tires are the enterprise will be scrapped automobiles recycling of used for urban sculpture design just now[15].

\section{Reverse design as new high ground of retrieving and dismantling scrapped automobiles enterprises development}

You've already talked about, retrieving and dismantling scrapped automobiles and reuse is the important link to realize the sustainable development of auto industry, but how the whole industry chain in automobile industry needs new development ideas. Profit is always limited, how to let OEMs, parts factory, vehicle maintenance and repair services are willing or active participation in? First, you need to rely on to guide policy guidance and industry regulations and constraints, the enterprise performance of the car scrap recycling industry corresponding responsibilities and obligations, including those from scrap car recycling and utilization of qualified parts, auto forward development were considered in the design and manufacture stage whether in products and recycle and reuse, dissembling environmental protection requirements in the future [16].

In addition to the industry regulations of mandatory, more important is to want from the technology of retrieving and dismantling scrapped automobiles industry and market point of view, create let OEMs, spare parts factory, automobile maintenance service enterprise pursuit of profit and the development space, to an actual enterprise active participation of the whole automobile industry chain and collaborative innovation development of scrap auto recycling industry [17]. This we must be good at mining car of retrieving and dismantling of the whole industry chain in the automobile industry gold mine, such as is the result of retrieving and dismantling scrapped automobiles firsthand material for automobile reverse design of large databases.

In general, the enclosed construction of retrieving and dismantling scrapped automobiles is mainly refers to the characteristics of the material circulation. We here at the same time is proposed for the car forward, reverse design of retrieving and dismantling scrapped automobiles closed system: not only can consider in the design of automobile is the future of retrieving and dismantling requirements of automotive of retrieving and dismantling process itself is the structure design of the reverse process, accumulated the massive databases can effectively guide the top-down design and production. Which makes the car of retrieving and dismantling is not just a "recycling company", but something really become automobile industry, become the important part of automobile industry chain.

There is no one company for companies on the market, all kinds of car after using the system analysis and study. Recycle and dismantling scrapped automobiles enterprises can form a professional team, specifically for recycling of massive traffic accident and natural end-oflife vehicles, construction vehicles before and after dismantling the system performance and the structure parameters of the components of this database, the classification of the development of automobile structure disassembly analysis and information management system, based on the failure characteristics, structural damage mechanism of all kinds of models, fatigue life and so on to carry out in-depth analysis and the statistical analysis of the system as well as the reverse design [18]. Related technical report in the vehicle and parts enterprises are not only has the extremely important guidance value in product development, can improve their joint participation in the enthusiasm of retrieving and dismantling scrapped automobiles, also promote our country automobile industry developed the core technology of the important support.

Recycle and dismantling scrapped automobiles enterprises can do nondestructive testing, which can also carry out a large number of key parts structure anatomy. Used for all kinds of models of fault characteristics, structure damage mechanism and fatigue life of the original accumulation of huge amounts of data is of the best sources of retrieving and dismantling scrapped automobiles such auto service industry [19]. This is why the initiative repair service industry also involved, they could understand more professional and more systematic data collected in the process of retrieving and dismantling scrapped automobiles hand from the data.

Therefore, for the auto reverse design of this database is the current scrap car recycling industry has not yet been digging "gold mine", is also based on the development of automobile industry chain of scrapped automobiles recycling industry one of the commanding heights.

\section{Summary}

Of retrieving and dismantling scrapped automobiles industry in China development present situation, take the sustainable development as a starting point, discusses the environmental protection laws and regulations under the constraints of industrial policy, relying on the dismantling of the high and new technology development and the coordinated development of the whole automobile industry chain strategy, also proposed the innovation for reverse design of retrieving and dismantling mass database service vehicle as the objective point of view.

In general, although "standard of automobile scrapping" has been revised for several revisions, strengthened the standardization of scrap work, but also further improvement should be made in the fields of relevant policies and regulations, strengthen law enforcement compulsory standards, improve dismantling technology and equipment level, strengthen the 
standardization of the enterprise management and improve the level of specialization. The industry sustainable healthy development of resource saving, ensure traffic safety and protect the environment, improve the comprehensive benefit, to promote coordinated development of society, economy and environment is a long-term and important significance. With courage and innovation ability of enterprise, retrieving and dismantling scrapped automobiles is not only a social responsibility endowed by the circular economy is to be gold mining cities.

\section{Acknowledgements}

The paper is jointly sponsored by the project from State key laboratory of advanced automobile body designing and manufacturing of Hunan University (No.71275003), National Science Fund for Distinguished Young Scholars (No.11225212) and the Specialized Research Fund for the Doctoral Program of Higher Education (No. 20120161130001).

\section{References}

1. Information http://www.12365auto.com/news/2014-1205/20141205090821.shtml.

2. Dismantling scrapped automobiles recycling situation in Japan and Korea, J. Non-Ferrous Metals Recycling and Utilization, 4 (2006)28-29.

3. Z.X. Fang, Overview of China's scrap remanufacturing related policies and standards for Automotive Recycling and parts, J. Automobile Parts, 1(2014)81-85.

4. Legislative Affairs Office of the State Council: Regulations on Dismantling scrapped vehicle recycling management(2010).

5. T. Wu, L.P. Chen, End-of-life Vehicle Recycling between China and Foreign Countries, J. Automobile Technology \& Material, 5, (2007) 12-15.

6. Z.W. Liu, Y. Zhang, Y. Yao, Study of the Current Situation and Countermeasure on Chinese Waste Automobiles Recovery, J. Value Engineering, 19 (2012) 308-309.
7. Y.Cai, status and Countermeasures on China's scrap auto recycling, J. China Resources Comprehensive Utilization, 2 (2009) 6-7.

8. A.G. LI, A.J. LI, China's current situation and development mode of scrap automobile recycling dismantling industry, J. China Resources Comprehensive Utilization, 6 (2012) 21-24.

9. J.Xu, The experience and Enlightenment of German scrap auto recycling, J. Jiangsu Commercial Forum, $4(2014) 15+18$.

10. Y.J. LI, Status and Suggestions on China's scrap auto recycling, J. Auto Industry Research, 11 (2010) 16-20.

11. Y.Z. Yao, Current Situation and Thinking of Management of Car Recycling In China, J. Automobile \& Parts, 4, (2011) 37-39.

12. Y.F. Shen, W. Yang, Status \& Prospecting Analysis on Chinese Scrap Car Recycling Industry, J. Automobile \& Parts, 5 (2009) 33-35.

13. M.L. LI, Research on scrap auto recycling system in America, J. Auto Industry Research, 2（2007） 4548.

14. Y.K. LI, Plans for Improving the Level of End-ofLife Vehicles Recycling Industry, J. Tianjin Auto, 12 (2010) 17-18.

15. B.X. Liu, The Status of Chinese Discarded Automobiles Disassembly and Recycling Industry and Countermeasure Research, J. Automobile \& Parts, 12 (2008) 43-45.

16. Y. Zhao, Y.C. Zhao, Research Progress of Recovery and Disposal of Abandoned Automobiles, J. Nonferrous Metals Engineering \& Research, 2-3 (2007) 103-112.

17. S. Chen, Recovering, Dismantling and Recycling of End-of-Life Vehicles, J. Automobile Technology \& Material, 7 (2007) 6-9.

18. D. Wu, Y. Lin, Y. Dai, Architectural Framework about Recycle of Waste Automobile, J. Logistics Sci-Tech, 3 ( 2007) 44-46.

19. X.P. Wang, T.Z. Zhang, Discussion of Automobile Recycling Standard in China, J. Automobile \& Parts,10 (2009) 42-45. 